\title{
Dress Designing Supply Chain Coordination Strategy and Application Research Based on Cloud Computing
}

\author{
Ran Duan ${ }^{1,}$, Xiaogang Liu ${ }^{1}$ \\ ${ }^{1}$ Fashion and Art Design Institute, Donghua University, Shanghai, China \\ aran_duan@126.com
}

Keywords: Cloud computing, Costume design, Supply chain, Collaborative strategy, Applied research

\begin{abstract}
With the increasing importance of cooperation between garment enterprises and garment supply chain management become the preferred way of collaboration between enterprises management. Cloud computing management way to promote the garment supply chain to make today's market competition has gradually become a supply chain on the basis of coordination to achieve win-win situation for the competition. Adhering to the predecessors' research results, this paper probes into the cloud computing environment of supply chain management related theory, the strategy of supply chain management problems, analyzed the supply chain performance measurement indicators, to determine the perspective of the supply chain enterprise collaborative management scheme is put forward.
\end{abstract}

\section{Introduction}

Cloud Computing is a Distributed Computing. At present, the understanding of cloud computing is the development and changes, cloud computing is no uniform definition [1]. China grid computing, cloud computing expert Liu peng gives the following definition: "the cloud computing task distribution in a large number of computer constitute pool of resources, can make all kinds of application system according to the need for computing power, storage space and all kinds of software service". Narrow cloud computing refers to the vendor by distributed computing and virtualization technologies to build data center or the super computer, free or on-demand rent the way to the technology developer or corporate clients providing services such as data storage, analysis and scientific computing [1]. Generalized by establishing a network server cluster cloud computing refers to the manufacturers, to provide a variety of different types of customers online software services, hardware, data storage, calculation and analysis on loan and other different types of services.

Traditional mode, the enterprise to establish a set of IT systems not only need to purchase hardware and other infrastructure, and buy software license, need special maintenance personnel. When enterprise scale will continue to upgrade all kinds of hardware and software facilities to meet the need [1]. For companies, computer hardware and software itself is not what they really need, they just finished the work, provide the efficiency of the tool. For an individual, we want to use the computer need to install many software normally, and many of the software is the charge, for users often do not use the software purchase is not cost-effective.

Now, cloud computing has been accepted by most of the enterprise, cloud applications are also beginning to popularity both at home and abroad, from all walks of life can be seen the shadow of a cloud computing. By the end of 2010, the domestic eight hundreds of cloud computing vendors has been successfully applied to study the cloud seven categories of more than 20 sub industries, formal user has more than 10000, the boom of cloud computing is more and more big, the scope is also more and more widely.

\section{Costume design information of supply chain coordination under the cloud computing environment}

Costume design information of supply chain coordination. "Costume design supply chain information collaboration" refers to the information technology to achieve garment design between 
members of the supply chain partners format of graduation thesis of the information system integration, to achieve operational data, market data and other information sharing and real-time communication, so as to realize garment design faster, better coordination between supply chain partners response terminal customers' requirements [2]. Can be seen from the above definition, costume design collaborative supply chain information mainly includes three aspects: one is to make full use of modern information technology to realize garment design supply chain information system integration; Second, real time data information share and exchange; Three is the dress designing, the coordination and cooperation between supply chain partners, to achieve the same objective. Only to realize three aspects of the clothing design on supply chain, supply chain collaborative clothing design can be called information, to achieve costume design goals of supply chain.

Software as a Service SaaS (Software - as - a - Service) application in synergy. Early costume design of supply chain enterprise information construction lack of more stringent overall planning, or in the process of implementation, the enterprise internal management needs changed, combined with the different system developers have their own style [2]. Therefore, even if did very scientific overall planning in the information construction of enterprise, enterprise implementation of information systems there are likely to be function overlap, lack of leakage and mutually connected. Therefore, from the fashion design business unified management of the supply chain mode, the existing various enterprise systems are at the same time, but also through the system on the synergy to reach the company internal same connection and coordination between function subsystem. From the synergy between the existing enterprise information systems to achieve finally comes at a cost to the costume design in the supply chain coordination and synergy effect is not ideal.

The emergence of cloud computing makes the clothing design information in the collaborative supply chain cooperation among different systems of different enterprises to become more simple, feasible and reliable, cloud computing services provided by the SaaS, is mature, with the development of the Internet and application software on the market arisen a completely innovative software application mode [3]. It is a kind of through the Internet provide software model, the unified plan of the SaaS provider will application software on the server, the customer can according to your actual demand, order via the Internet service provider for application software services, and through the Internet service providers to provide services [3]. Dress designing supply chain enterprises don't have to buy the software, and use the cloud computing service providers to rent the web-based software, the operation of the supply chain to manage the clothing design of cloud computing services management and maintenance of software, software vendors to provide Internet applications at the same time, also provide software offline operation and local data storage, let users can use it anywhere, anytime and order of software and services.

Huge amounts of data distributed storage technology in the application of collaborative. Any fashion design in the supply chain process generated by the data volume is huge, so dress design of supply chain information storage is huge. The emergence of cloud computing provides clothing design information of supply chain coordination with huge amounts of data storage, cloud computing service providers need to garment design in the supply chain distribution, vast amounts of data processing and analysis [3]. Cloud computing system is composed of a large number of servers, and supply chain services for dress design, so the cloud computing system with the method of distributed storage to store data, make better use of redundant storage reliability of the data.

Virtualization technology application in synergy. Costume design different or the same enterprise supply chain system design and system interface is different, this is dress designing supply chain information collaboration must solve one problem [4]. Cloud computing service provider of virtualization technology clothing design can be different systems of different interface software of virtual supply chain enterprise into the same interface, the same system to achieve the garment design, clothing design between supply chain enterprises within the supply chain system with the enterprise system of data between the synergy, program, coordination and interface coordination. Through virtualization technology can realize software applications and the underlying hardware isolated, it will include the splitting of a single resource into multiple virtual resource model, or multiple resources integration into a virtual resource aggregation patterns. 


\section{Costume design information of supply chain coordination under cloud computing environment risk analysis}

Costume design information transmission has been information distortion in supply chain information collaboration, information delay as well as the influence of the "bullwhip effect", and as a result of the information management technology updated quickly, more resources, makes the information work gradually become a costume design of supply chain management difficulty, urgent need to seek a new solution model, the emergence of cloud computing provides the reliable technology for garment design information of supply chain coordination [4]. Dress designing supply chain will cloud computing service providers as garment design supply chain management, information management of the third party information costume design between supply chain enterprises and cloud computing service providers shall be entrusted with the agency relationship.

Costume design information risk of adverse selection of partners. Costume design each node enterprises of supply chain, the business is also a kind of principal-agent relationship between supplier is the agent, the purchaser is the delegate. Because of information asymmetry, the principal-agent relationships often lead to an adverse selection risk [4]. Clients tend to suffer more than the agent position, companies often by increasing the asymmetry of information, get more interest from partners. Can be seen from the partners of the adverse selection risk graduation thesis format, enterprises to choose the right partners is very important, improper selection will reduce enterprise profit, increase the whole costume design in the supply chain operating costs.

Costume design moral hazard of nodal enterprises of the supply chain. Costume design each node enterprises of supply chain emphasized in the process of cooperation on the basis of information sharing to achieve a win-win situation, but the actual cooperation in the process of their business exclusive, with the instinct of the pursuit of self-interest maximization [5]. In interests conflict, members of the enterprise from its own perspective, the use of information advantages and take some contrary to the interests of the whole supply chain of garment design or other measures for the interests of the member enterprises of supply chain of garment design, so in the clothing design information of supply chain coordination in the process of the implementation of the moral risk, the risk has a harmful effect on garment design efficient and effective supply chain.

Costume design hidden information risk of supply chain. Dress designing supply chain is made up of the existence of independent economic entity of virtual organization, each node enterprise has interest goal and development strategy [5]. In information sharing and possible brings to the enterprise itself, such as enterprise core technology, financial data and other confidential information leaked out, and these will lead to a serious loss of enterprise core competitiveness. As the main body, rational enterprise either the principal or the agent, from the perspective of their own will naturally conceal some core confidential information, it gives the whole costume design running speed and stability of the supply chain have a negative impact.

Dress designing supply chain and cloud computing service providers of the principal-agent relationship between the information risk. Cloud computing environment for cloud computing service providers is a costume design collaborative supply chain information third-party neutral and credibility problems of managers [6]. Cloud computing service provider if you can't very good set up their own neutral and credibility, so it is hard to own clothing design supply chain enterprise the core of the information resources entrusted to a distrust of a third party. This gives of garment design and garment design information of supply chain coordination supply chain operation has brought the huge impact.

Costume design between supply chain and cloud computing service provider network connection and the speed of risk. 1) cloud computing services in the clothing design network connection of supply chain information collaboration requires constant Chinese paper database. Because the user need to connect through the Internet applications and documents, if there were no Internet connection, because some emergency dress designing supply chain will can't do anything.2) cloud computing services in the clothing design information of supply chain coordination requires high speed network environment [6]. Cloud service under the environment of low network 
connection will not work very well. Because Web applications require a lot of bandwidth to download, in low page loads under the network environment is hard, let alone to use its rich features.

Costume design between supply chain and cloud computing service provider of information security risk [7]. 1) because the dress designing supply chain enterprise to their respective data storage in the cloud, so the data is stored in the cloud security check need to be done in the case of can't grasp the global data. Considering the clothing design of supply chain enterprise data stored in the cloud diversity and the safe storage of the need for a long time, check the cloud data security faced with greater challenges.2) the cloud supply chain information update frequency soon, including insert, delete, update, add and reordering, etc. In the case of dynamic update to ensure the accuracy of the data is vital, but dynamic failure makes the traditional technology, we must find new ways. 3) dress designing supply chain information together in a single garment design of supply chain enterprise information using data redundancy is stored in multiple physical space, in order to reduce the threat of data integrity, therefore, distributed data accuracy verification of protocol is practical cloud data storage safe and sound in the crucial factor. So, at the same time of enjoying convenient cloud computing service, information resource for cloud computing data warehouse safety management and puts forward the new demand.

\section{Summary}

With the increasing importance of cooperation between garment enterprises and garment supply chain management become the preferred way of collaboration between enterprises management. But cloud computing environment dress designing supply chain information collaboration also there exists a social and technical risk, the risk analysis is the use of information resources management of related principles and theoretical analysis of garment design information of supply chain coordination, in order to fashion design information of supply chain coordination under the cloud computing environment can be more smooth and clear development direction.

\section{Acknowledgement}

This project, Construction of Creative Design and Public Service Base-A Study Based on Cloud Computing, is supported by Special Foundation for Significant Development Fund Projects of National Independent Innovation Demonstration Zone in Zhangjiang, Shanghai.

\section{References}

[1] W.L. Xue, Costume design information risk of supply chain in e-commerce environment of fuzzy evaluation. Journal of Dalian maritime university, vol.2, pp.100, 2011.

[2] W.J. Qian, Cloud computing and information resource sharing management, library and intelligence, Vol.4, pp.41-49, 2009.

[3] J.Q. Liu, Supply Chain Inventory Management and the Value of Shared Information, People's education press, 2006, pp.45-48.

[4] L.L. Wang, Clothing enterprise sales logistics and supply chain management pattern research, market modernization, vol.523, pp.32-37, 2008.

[5] L.Y. Zhou and Q.W. Zhu, Apparel group supply chain strategy and management, logistics technology, vol. 26, pp. 2-6, 2011.

[6] H.J. Li, The clothing enterprise sales logistics information management system of the building, China textile publishing house, vol.10, pp.43-48, 2010.

[7] R.Ch. Deng, Garment industry supply chain management, China textile publishing house, vol.3, pp.51-55, 2013. 